\title{
Prognostic Value of Heart Rate Profiles During Cardiopulmonary Exercise Testing in Patients With Cardiac Disease
}

Ayumi GodA, ${ }^{1,2}$ MD, Akira KoIKe, ${ }^{1} \mathrm{MD}$, Masayo Hoshimoto-Iwamoto, ${ }^{1,3} \mathrm{PhD}$, Osamu Nagayama, ${ }^{1}$ BS, Kaori Yamaguchi, ${ }^{1}$ BS, Akihiko Tajima, ${ }^{1}$ BS, Hitoshi Sawada, ${ }^{1}$ MD, Haruki ITOH, ${ }^{4} \mathrm{MD}$, Mitsuaki Isobe, ${ }^{2} \mathrm{MD}$, and Tadanori AIZAWA, ${ }^{1} \mathrm{MD}$

\section{SUMMARY}

Earlier studies have demonstrated that an impaired capacity to increase heart rate (HR) and a slowed HR recovery following exercise are both associated with cardiovascular mortality. We sought to determine whether HR profiles during exercise testing are superior to respiratory gas parameters in predicting mortality among patients with cardiac disease.

Five-hundred and fifty stable cardiac patients $(63.4 \pm 9.9$ years $)$ underwent a symptom-limited incremental exercise test. Measurements included peak $\mathrm{VO}_{2}, \mathrm{VE} / \mathrm{VCO}_{2}$ slope, HR increase (HR difference from rest to peak exercise), and HR recovery (HR difference from peak to 2 minutes after exercise). Twenty-eight cardiovascular-deaths occurred during 4 years of prospective follow-up. In multivariate analysis, the CPX parameters were found to be significant predictors of cardiovascular-death; peak $\mathrm{VO}_{2}$ (relative risk (RR), $3.44 ; 95 \%$ CI 1.37 to $8.62 ; P=0.008$ ), $\mathrm{VE} / \mathrm{VCO}_{2}$ slope (RR, $1.52 ; 95 \%$ CI 1.11 to 2.08 ; $P=0.009)$, while HR increase and HR recovery were determined not to be independent predictors.

Although HR profiles during exercise testing are easy to perform and useful as prognostic predictors in patients with cardiac disease, they are not superior to respiratory gas analysis. (Int Heart J 2009; 50: 59-71)

Key words: Cardiopulmonary exercise testing, Heart rate, Prognosis

PARAMETERS obtained from cardiopulmonary exercise testing (CPX) reflect the severity of heart disease and the activities of daily living in cardiac patients. The widely used CPX parameters are peak oxygen uptake $\left(\mathrm{VO}_{2}\right)$, gas exchange (anaerobic) threshold, ratio of the increase in $\mathrm{VO}_{2}$ to the increase in work rate (WR) $\left(\Delta \mathrm{VO}_{2} / \Delta \mathrm{WR}\right)$, and the slope of the increase in ventilation (VE) to the

From ${ }^{1}$ The Cardiovascular Institute, ${ }^{2}$ Department of Cardiovascular Medicine, Tokyo Medical and Dental University, Tokyo, ${ }^{3}$ School of Health and Sports Science, Juntendo University, Chiba, and ${ }^{4}$ Sakakibara Heart Institute, Tokyo, Japan.

Address for correspondence: Ayumi Goda, MD, The Cardiovascular Institute, 7-3-10 Roppongi, Minato-ku, Tokyo 106-0032, Japan.

Received for publication July 18, 2008.

Revised and accepted October 9, 2008. 
increase in $\mathrm{CO}_{2}$ output $\left(\mathrm{VCO}_{2}\right)\left(\mathrm{VE} / \mathrm{VCO}_{2}\right.$ slope $)$. Landmark studies have established peak $\mathrm{VO}_{2}$ as the key measure of exercise physiology, and low peak $\mathrm{VO}_{2}$ is widely recognized as a predictor of poor prognosis. ${ }^{1)}$ Peak $\mathrm{VO}_{2}$ is derived from the Fick equation, and most patients achieve comparable arterial-venous oxygen differences when they give maximal effort. Peak $\mathrm{VO}_{2}$ thus serves as a noninvasive marker for peak cardiac output response and cardiac reserve. VE/ $\mathrm{VCO}_{2}$ slope, an index of ventilatory efficiency, also serves as a prognostic predictor. ${ }^{2,3)}$ The most meaningful determinants are the matching of ventilation and perfusion. The reliability of CPX parameters in predicting cardiovascular events and death is undisputable.

Recent research has revealed that the autonomic nervous system also plays a significant role in cardiac arrhythmia and prognosis. Studies of markers for vagal tone and autonomic imbalance have shown that an elevated resting heart rate (HR), impaired HR recovery from exercise, suppressed peak HR, low HR variability, decreased baroreflex, and decreased baroreflex sensitivity are all predictive of cardiovascular events. ${ }^{4-7)}$ HR profiles can be measured easily throughout ordinary exercise testing without respiratory gas analysis. It remains unclear, however, whether HR profiles have more prognostic value than the established CPX parameters. The aim of this study was to determine whether HR profile analysis during exercise testing is more predictive of cardiovascular death than the measurement of CPX parameters in cardiac patients.

\section{Methods}

Study patients: We prospectively studied 571 consecutive patients with cardiovascular disease who underwent CPX between February 2001 and August 2003. The exercise testing was performed to evaluate exercise capacity or cause of dyspnea. Patients with lung disease or cerebrovascular disease diagnosed by clinical documentation, patients with ischemic heart disease who stopped exercise testing due to chest pain or significant ST depression in exercise ECG, and patients with implanted pacemakers were excluded from the study. After excluding these patients, 550 patients remained and were included in the analysis.

The patient population consisted of 438 males and 112 females, with an average age of $63.4 \pm 9.9$ years. The mean left ventricular ejection fraction (LVEF) was $59.4 \pm 16.0 \%$. Seventy-three patients were in atrial fibrillation. The underlying heart diseases included ischemic heart disease with some treatment interventions in 339 patients, valvular heart disease in 156, idiopathic dilated cardiomyopathy in 32 , hypertrophic cardiomyopathy in 21 , and other cardiovascular diseases in 2.

Medications influencing hemodynamic variables included nitrates (pre- 
scribed in 270 patients), calcium-channel blockers (250 patients), $\beta$-blockers (207 patients), diuretics (137 patients), angiotensin-receptor blockers (124 patients), angiotensin-converting enzyme inhibitors (99 patients), digitalis (70 patients), and spironolactone (54 patients).

The protocol and procedures for the exercise testing were approved by the Human Subjects Committee of each participating institution. Each patient provided informed consent to participate in the study after being given an explanation of the purposes and risks of the study.

Exercise testing: An incremental symptom-limited exercise test was performed using an upright, electromagnetically braked cycle ergometer (Corival 400; Lode; Groningen, Holland) according to the Ramp protocol. The test consisted of a 4-minute resting period, followed by 4 minutes of warm-up at an ergometer setting of $0 \mathrm{~W}$ or $20 \mathrm{~W}(60 \mathrm{rpm})$, followed by testing with a $1 \mathrm{~W}$ increase in exercise load every 6 seconds ( $10 \mathrm{~W} /$ minute). After achieving peak workload, all the patients spent at least 1 minute in cool-down at $0 \mathrm{~W}$. During recovery, the subjects remained in the upright position on the cycle ergometer until the end of the 6th minute. ECG was monitored continuously during the test (System ML-6500; Fukuda Denshi Co. Ltd., Tokyo). Cuff blood pressure was measured at rest on the cycle ergometer, once every minute during the test, and once every minute after the completion of the test up to the 6th minute of recovery, using an automatic indirect manometer (STBP-780; Nippon Colin Co. Ltd.; Aichi, Ja$\operatorname{pan})^{8)}$

HR profiles: We examined data on the subjects' resting HR, the increase in HR from rest to peak exercise (HR increase), and the decrease in HR from peak exercise to 2 minutes after the termination of exercise (HR recovery). The resting HR was the average HR during the 4-minute resting period. HR increase was determined as the difference from resting HR to peak HR, and HR recovery was determined as a difference from peak $\mathrm{HR}$ to $\mathrm{HR}$ at 2 minutes after exercise.

Respiratory gas analysis: $\mathrm{VO}_{2}, \mathrm{VCO}_{2}$, and $\mathrm{VE}$ were measured throughout the test using an Aeromonitor AE-300S (Minato Medical Science; Osaka, Japan). ${ }^{9,10)}$ Prior to calculating the parameters from respiratory gas analysis, a 5-point moving average of the breath-by-breath data was obtained. Peak $\mathrm{VO}_{2}$ was defined as the average value obtained during the last 15 seconds of incremental exercise. $\Delta$ $\mathrm{VO}_{2} / \Delta \mathrm{WR}$ was calculated from the data recorded between 30 seconds after the start of incremental exercise to 30 seconds before the end of exercise, by least squares linear regression. ${ }^{11)} \mathrm{VE} / \mathrm{VCO}_{2}$ slope was calculated from the start of incremental exercise to the respiratory compensation point, by least squares linear regression as previously described. ${ }^{11,12)}$

Endpoint: The primary endpoint was death due to a cardiovascular cause. Vital status was assessed by investigation of the hospital information system. 
Statistics: Clinical and exercise variables for survivors and nonsurvivors were compared through the use of $\chi^{2}$ tests (categorical variables) and unpaired $t$ tests (continuous variables). HR measurements were nonnormally distributed, and thus were compared by the Mann-Whitney U test.

Lower peak $\mathrm{VO}_{2}$, lower $\Delta \mathrm{VO}_{2} / \Delta \mathrm{WR}$, lower HR increase, lower HR recovery, and lower LVEF have been associated with a poor prognosis in a previous study, so cut-off values were based on $25^{\text {th }}$ percentiles. In the same way, a higher $\mathrm{VE} / \mathrm{VCO}_{2}$ slope and higher age have been related to a poor prognosis, therefore, the cut-off value was based on $75^{\text {th }}$ percentiles, as appropriate (Cut-off values; peak $\mathrm{VO}_{2}: 14.5 \mathrm{~mL} / \mathrm{minute} / \mathrm{kg}, \mathrm{VE} / \mathrm{VCO}_{2}$ slope: $35.8, \Delta \mathrm{VO}_{2} / \Delta \mathrm{WR}: 8 \mathrm{~mL} /$ minute/W, HR increase: $35 \mathrm{bpm}$, HR recovery: $22 \mathrm{bpm}$, LVEF: 50\%, age: 70 years old). The relationships between the tertiles of HR increase, HR recovery, peak $\mathrm{VO}_{2}$, and $\mathrm{VE} / \mathrm{VCO}_{2}$ slope with mortality were evaluated by Kaplan-Meier analysis. Patients who died of cancer were excluded from the survival analyses.

The association between the variables and mortality was assessed using Cox proportional hazards models for both categorical and continuous values. All continuous variables were standardized and included as such in Cox survival analyses to avoid artifacts of dichotomization. The hazard ratios are reported for a 1-SD increase or decrease in each variable.

All analyses were performed using the SPSS statistical package, version 11.0 (SPSS Inc., Chicago). Statistical comparisons were considered significant when the probability values were less than 0.05 .

\section{RESULTS}

Baseline characteristics: After 1,392 \pm 637 days (3.8 years) of prospective follow-up, 28 cardiovascular deaths and 1 cancer death had occurred. The causes of cardiovascular death included progressive heart failure in 13 patients, sudden cardiac death in 13 , acute myocardial infarction in 1 , and cerebrovascular disease in 1.

Among the patients with coronary artery disease, 53 received percutaneous coronary intervention and 5 underwent coronary artery bypass graft surgery during the follow-up period. Twenty-five of the patients with valvular disease underwent cardiac valve replacement and/or repair during the follow-up. Two of the patients with coronary artery disease underwent cardioverter-defibrillator implantation.

Table I shows a comparison of the clinical characteristics between survivors and nonsurvivors. Nonsurvivors were significantly older, and had a significantly lower LVEF and higher incidence of atrial fibrillation than survivors.

HR responses: The HR responses to exercise according to outcome are de- 
Table I. Baseline Characteristics

\begin{tabular}{|c|c|c|c|c|}
\hline Characteristic & $\begin{array}{l}\text { All Patients } \\
\quad(n=549)\end{array}$ & $\begin{array}{l}\text { Survivors } \\
(n=521)\end{array}$ & $\begin{array}{l}\text { Nonsurvivors } \\
\quad(n=28)\end{array}$ & $P$ \\
\hline Age (years) & $63.4 \pm 9.9$ & $63.2 \pm 10.6$ & $67.7 \pm 9.3$ & 0.028 \\
\hline Male/female & $437 / 112$ & $413 / 108$ & $24 / 4$ & 0.411 \\
\hline $\mathrm{HT}(\mathrm{cm})$ & $163.4 \pm 8.0$ & $163.5 \pm 8.0$ & $161.0 \pm 8.1$ & 0.102 \\
\hline $\mathrm{BW}(\mathrm{kg})$ & $62.1 \pm 10.8$ & $62.3 \pm 10.8$ & $58.0 \pm 9.9$ & 0.040 \\
\hline BMI & $23.2 \pm 3.1$ & $23.2 \pm 3.1$ & $22.3 \pm 2.9$ & 0.132 \\
\hline \multicolumn{5}{|l|}{ Etiology } \\
\hline Ischemic heart disease & $338(62 \%)$ & $324(62 \%)$ & $14(50 \%)$ & 0.175 \\
\hline Valvular heart disease & $156(28 \%)$ & $145(28 \%)$ & $11(39 \%)$ & 0.167 \\
\hline Idiopathic dilated cardiomyopathy & $32(6 \%)$ & $31(6 \%)$ & $1(4 \%)$ & 0.485 \\
\hline Hypertrophic cardiomyopathy & $21(4 \%)$ & $19(4 \%)$ & $2(7 \%)$ & 0.305 \\
\hline Other cardiovascular disease & $2(0.4 \%)$ & $2(0.4 \%)$ & 0 & 0.897 \\
\hline Presence of atrial fibrillation & $73(13.3 \%)$ & $63(12.1 \%)$ & $10(35.7 \%)$ & 0.002 \\
\hline \multicolumn{5}{|l|}{ Medication } \\
\hline Nitrates & $269(49 \%)$ & $254(48 \%)$ & $15(54 \%)$ & 0.429 \\
\hline Calcium-channel blockers & $249(45 \%)$ & $241(46 \%)$ & $8(29 \%)$ & $<0.001$ \\
\hline$\beta$-Blockers & $206(38 \%)$ & $195(37 \%)$ & $11(39 \%)$ & 0.713 \\
\hline Diuretics & $137(25 \%)$ & $121(23 \%)$ & $16(57 \%)$ & 0.002 \\
\hline Angiotensin-receptor blockers & $134(24 \%)$ & $124(24 \%)$ & $10(36 \%)$ & 0.008 \\
\hline Angiotensin-converting enzyme inhibitors & $104(19 \%)$ & $99(19 \%)$ & $5(18 \%)$ & 0.960 \\
\hline Digitalis & $70(13 \%)$ & $64(12 \%)$ & $6(21 \%)$ & 0.012 \\
\hline Spironolactone & $54(10 \%)$ & $46(9 \%)$ & $8(29 \%)$ & $<0.001$ \\
\hline $\operatorname{LVEF}(\%)$ & $59.3 \pm 16.0$ & $60.4 \pm 14.7$ & $40.9 \pm 22.0$ & $<0.001$ \\
\hline
\end{tabular}

Data presented are the mean value \pm SD. HT indicates height, BW, body weight, BMI, body mass index; and LVEF, left ventricular ejection fraction.

Table II. HR at Rest and Changes During and After Exercise

\begin{tabular}{lrrrr}
\hline Variable & $\begin{array}{c}\text { All Patients } \\
(n=549)\end{array}$ & $\begin{array}{c}\text { Survivors } \\
(n=521)\end{array}$ & $\begin{array}{c}\text { Nonsurvivors } \\
(n=28)\end{array}$ & $P$ \\
\hline Rest HR $(\mathrm{bpm})$ & $76.5 \pm 14.1$ & $76.5 \pm 14.2$ & $76.6 \pm 12.6$ & 0.976 \\
Peak HR (bpm) & $128.7 \pm 23.8$ & $129.5 \pm 23.6$ & $113.8 \pm 21.6$ & 0.001 \\
HR increase $(\mathrm{bpm})$ & $52.2 \pm 22.2$ & $53.1 \pm 22.0$ & $37.2 \pm 20.6$ & $<0.001$ \\
HR recovery (bpm) & $32.6 \pm 14.8$ & $33.0 \pm 14.7$ & $24.3 \pm 14.8$ & 0.002 \\
Rest SBP $(\mathrm{mmHg})$ & $125.7 \pm 19.8$ & $126.0 \pm 24.9$ & $120.8 \pm 24.9$ & 0.180 \\
Rest DBP $(\mathrm{mmHg})$ & $71.3 \pm 11.4$ & $71.7 \pm 11.3$ & $64.8 \pm 11.6$ & 0.002 \\
Peak SBP $(\mathrm{mmHg})$ & $186.2 \pm 34.5$ & $187.9 \pm 33.9$ & $155.3 \pm 31.0$ & $<0.001$ \\
Peak DBP $(\mathrm{mmHg})$ & $86.3 \pm 16.6$ & $86.7 \pm 16.7$ & $78.6 \pm 14.3$ & 0.012 \\
\hline
\end{tabular}

Data presented are the mean value $\pm \mathrm{SD}$.

HR indicates heart rate; SBP, systolic blood pressure; and DBP, diastolic blood pressure.

scribed in Table II. Peak HR, HR increase, HR recovery, and peak SBP were significantly lower in nonsurvivors than in survivors.

Exercise test response: Table III presents the exercise test responses according to outcome status. Nonsurvivors had significantly lower peak $\mathrm{VO}_{2}$, higher $\mathrm{VE} / \mathrm{VCO}_{2}$ slope, lower $\Delta \mathrm{VO}_{2} / \Delta \mathrm{WR}$, and lower peak WR than survivors. The respiratory exchange ratio (ie, $\mathrm{VCO}_{2} / \mathrm{VO}_{2}$ ) in nonsurvivors was similar to that in 
Table III. Respiratory Gas Parameters

\begin{tabular}{|c|c|c|c|c|}
\hline Variable & $\begin{array}{l}\text { All Patients } \\
(n=549)\end{array}$ & $\begin{array}{l}\text { Survivors } \\
(n=521)\end{array}$ & $\begin{array}{c}\text { Nonsurvivors } \\
\quad(n=28)\end{array}$ & $P$ \\
\hline Peak $\mathrm{VO}_{2}(\mathrm{~mL} /$ minute/kg) & $18.2 \pm 5.3$ & $18.5 \pm 5.2$ & $12.3 \pm 3.5$ & $<0.001$ \\
\hline$\Delta \mathrm{VO}_{2} / \Delta \mathrm{WR},(\mathrm{mL} /$ minute/W) & $9.1 \pm 2.3$ & $9.2 \pm 2.2$ & $6.8 \pm 2.2$ & $<0.001$ \\
\hline $\mathrm{VE} / \mathrm{VCO}_{2}$ slope & $32.7 \pm 8.0$ & $32.2 \pm 7.3$ & $43.1 \pm 11.9$ & $<0.001$ \\
\hline Peak WR (W) & $89.3 \pm 32.0$ & $90.9 \pm 31.6$ & $58.9 \pm 22.5$ & $<0.001$ \\
\hline Peak R & $1.090 \pm 0.092$ & $1.090 \pm 0.093$ & $1.079 \pm 0.085$ & 0.496 \\
\hline
\end{tabular}

Data presented are the mean value $\pm \mathrm{SD}$.

$\mathrm{VO}_{2}$ indicates $\mathrm{O}_{2}$ uptake; WR, work rate; $\mathrm{VE}$, ventilation; $\mathrm{VCO}_{2}, \mathrm{CO}_{2}$ output; and $\mathrm{R}$, respiratory exchange ratio.

Table IV. Univariate Predictors of Death

\begin{tabular}{lcccc}
\hline Variable & Relative Risk & $95 \% \mathrm{CI}$ & Chi-square & $P$ \\
\hline${\text { Peak } \mathrm{VO}_{2}}^{\text {VE/ } / \mathrm{CO}_{2} \text { slope }}$ & 4.79 & $2.92-7.91$ & 38.50 & $<0.0001$ \\
$\mathrm{HR}$ increase & 2.24 & $1.81-2.77$ & 53.74 & $<0.0001$ \\
$\mathrm{HR}$ recovery & 2.42 & $1.53-3.77$ & 14.89 & $<0.0001$ \\
Peak WR & 2.04 & $1.33-3.17$ & 10.43 & 0.001 \\
$\Delta$ VO $/ \Delta$ WR & 3.95 & $2.48-6.54$ & 31.48 & $<0.0001$ \\
LVEF & 2.44 & $1.87-3.18$ & 44.11 & $<0.0001$ \\
Peak SBP & 2.69 & $1.95-3.67$ & 37.26 & $<0.0001$ \\
Atrial fibrillation & 2.76 & $1.87-4.24$ & 23.67 & $<0.0001$ \\
Rest HR & 3.35 & $1.56-7.20$ & 9.55 & 0.002 \\
Rest SBP & 1.00 & $0.69-1.43$ & 0.01 & 0.977 \\
Age & 1.35 & $0.91-1.98$ & 2.06 & 0.151 \\
Male & 1.56 & $1.04-2.35$ & 4.57 & 0.033 \\
BMI & 1.46 & $0.51-4.20$ & 0.49 & 0.486 \\
$\beta$ Blocker use & 1.37 & $0.93-2.01$ & 2.53 & 0.112 \\
Ischemic heart disease & 1.09 & $0.51-2.33$ & 0.05 & 0.825 \\
\hline
\end{tabular}

Except for the variables male, atrial fibrillation, $\beta$ blocker use, and ischemic heart disease, the relative risks were calculated for a change of 1-SD.

$\mathrm{CI}$ indicates confidence interval; $\mathrm{VO}_{2}, \mathrm{O}_{2}$ uptake; VE, ventilation; $\mathrm{VCO}_{2}, \mathrm{CO}_{2}$ output; WR, work rate; LVEF, left ventricular ejection fraction; SBP, systolic blood pressure; HR, heart rate; SBP, systolic blood pressure; and BMI, body mass index.

survivors.

Outcome: Univariate analyses. Table IV presents the univariate predictors of death. The prognostic significance of the measurements was assessed by testing variables as continuous values using Cox regression analysis. When evaluating as univariate predictors, peak $\mathrm{VO}_{2}$ (relative risk (RR), 4.79; 95\% CI 2.92 to 7.91; $P<0.0001)$ had the highest significance, followed by $\mathrm{VE} / \mathrm{VCO}_{2}$ slope $(\mathrm{RR}$, 2.24; $95 \%$ CI 1.81 to $2.77 ; P<0.0001), \Delta \mathrm{VO}_{2} / \Delta \mathrm{WR}$ (RR, 2.44; $95 \%$ CI 1.87 to $3.18 ; P<0.0001$ ), peak WR (RR, 3.95; 95\% CI 2.48 to $6.54 ; P<0.0001$ ), HR increase (RR, 2.42; 95\% CI 1.53 to $3.77 ; P<0.0001)$, HR recovery (RR, $2.04 ; 95 \%$ CI 1.33 to $3.17 ; P=0.001$ ), $\operatorname{LVEF}$ (RR, $2.69 ; 95 \%$ CI 1.95 to $3.67 ; P$ $<0.0001$ ), peak SBP (RR, 2.76; $95 \%$ CI 1.87 to $4.24 ; P<0.0001)$, presence of 
Table V. Multivariate Predictors of Death

\begin{tabular}{|c|c|c|c|c|}
\hline Variable & Relative Risk & $95 \% \mathrm{CI}$ & Chi-square & $P$ \\
\hline \multicolumn{5}{|l|}{ Model 1 (continuous variables) } \\
\hline LVEF & 2.16 & $1.52-3.03$ & 19.47 & $<0.0001$ \\
\hline Peak $\mathrm{VO}_{2}$ & 3.44 & $1.37-8.62$ & 6.93 & 0.008 \\
\hline $\mathrm{VE} / \mathrm{VCO}_{2}$ slope & 1.52 & $1.11-2.08$ & 6.92 & 0.009 \\
\hline$\Delta \mathrm{VO}_{2} / \Delta \mathrm{WR}$ & 1.43 & $0.90-2.27$ & 2.33 & 0.127 \\
\hline HR increase & 1.05 & $0.43-2.60$ & 0.01 & 0.908 \\
\hline HR recovery & 1.41 & $0.66-3.07$ & 0.76 & 0.383 \\
\hline Atrial fibrillation & 1.67 & $0.65-4.29$ & 1.13 & 0.287 \\
\hline Age & 1.76 & $0.85-3.63$ & 2.34 & 0.126 \\
\hline \multicolumn{5}{|l|}{ Model 2 (categorical variables) } \\
\hline Low LVEF $(\leqq 50 \%)$ & 7.47 & $3.26-17.11$ & 22.58 & $<0.0001$ \\
\hline Low Peak $\mathrm{VO}_{2}(<14.5 \mathrm{~mL} /$ minute $/ \mathrm{kg})$ & 2.75 & $1.01-7.50$ & 3.89 & 0.049 \\
\hline High VE/VCO ${ }_{2}$ slope $(>35.8)$ & 4.43 & $1.70-11.52$ & 9.29 & 0.002 \\
\hline Low $\Delta \mathrm{VO}_{2} / \Delta \mathrm{WR}(<8 \mathrm{~mL} /$ minute $/ \mathrm{W})$ & 1.87 & $0.78-4.50$ & 1.95 & 0.162 \\
\hline Low HR increase $(<35 \mathrm{bpm})$ & 2.87 & $0.97-8.47$ & 3.65 & 0.056 \\
\hline Low HR recovery (<22 bpm) & 1.22 & $0.48-3.14$ & 0.17 & 0.677 \\
\hline Atrial fibrillation & 2.33 & $0.94-5.81$ & 3.31 & 0.069 \\
\hline High age ( $>70$ years old) & 1.58 & $0.70-3.57$ & 1.21 & 0.271 \\
\hline
\end{tabular}

Relative risks and CIs in Model 1 were calculated for a change of 1-SD.

$\mathrm{CI}$ indicates confidence interval; $\mathrm{VO}_{2}, \mathrm{O}_{2}$ uptake; VE, ventilation; $\mathrm{VCO}_{2}, \mathrm{CO}_{2}$ output; WR, work rate; LVEF, left ventricular ejection fraction; and HR, heart rate.

atrial fibrillation (RR, 3.35; 95\% CI 1.56 to $7.20 ; P<0.0001)$, and age (RR, 1.56; 95\% CI 1.04 to $2.35 ; P=0.033$ ).

Multivariate analyses. Although several variables were found to be associated with higher mortality in our study, the background characteristics of the patients might affect the outcome as confounding factors. To determine the independent effects of these variables on the prognosis, multivariate analysis was performed. The results of the multivariate analysis, using both continuous and categorical models, are shown in Table V.

Analyzing the variables as continuous, peak $\mathrm{VO}_{2}(\mathrm{RR}, 3.44 ; 95 \% \mathrm{CI} 1.37$ to $8.62 ; P=0.008), \mathrm{VE} / \mathrm{VCO}_{2}$ slope (RR, $1.52 ; 95 \% \mathrm{CI} 1.11$ to $2.08 ; P=0.009$ ), and LVEF (RR, 2.16; $95 \%$ CI 1.52 to $3.03 ; P<0.0001$ ) were determined to be strong independent predictors of survival. However, HR increase and HR recovery were determined to not be independent predictors.

In the same way, analyzing the variables as categorical, using cut-off values, a low peak $\mathrm{VO}_{2}(\mathrm{RR}, 2.75 ; 95 \% \mathrm{CI} 1.01$ to $7.50 ; P=0.049)$, high $\mathrm{VE} / \mathrm{VCO}_{2}$ slope (RR, 4.43; $95 \%$ CI 1.70 to $11.52 ; P=0.002$ ), and low LVEF (RR, 7.47; 95\% CI 3.26 to $17.11 ; P<0.0001)$ were found to be strong independent predictors of survival. However, HR increase and HR recovery were determined not to be independent predictors.

The results of Kaplan-Meier analysis of the relationships of peak $\mathrm{VO}_{2}, \mathrm{VE} /$ $\mathrm{VCO}_{2}$ slope, $\mathrm{HR}$ increase, $\mathrm{HR}$ recovery, and LVEF with cardiovascular mortality 


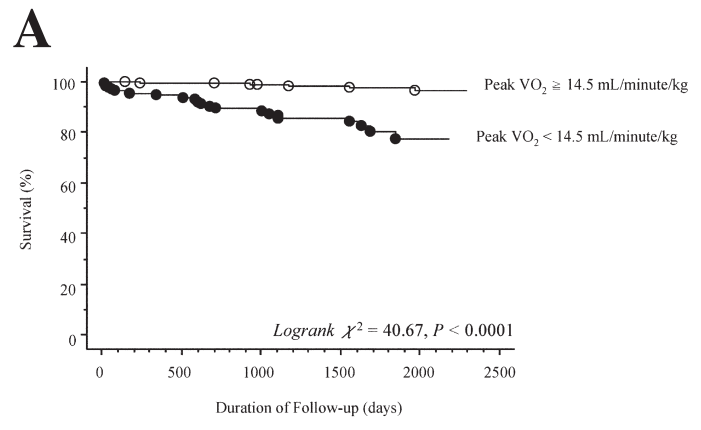

B

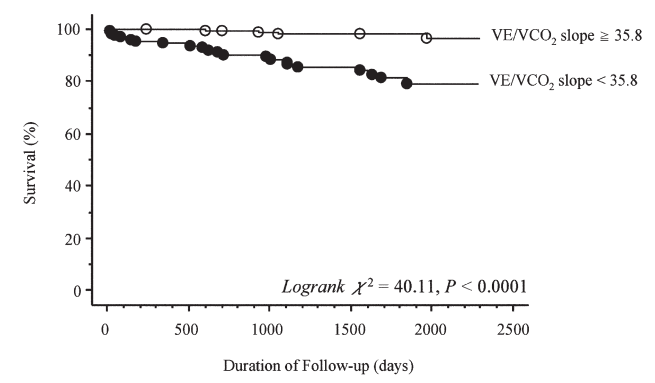

C
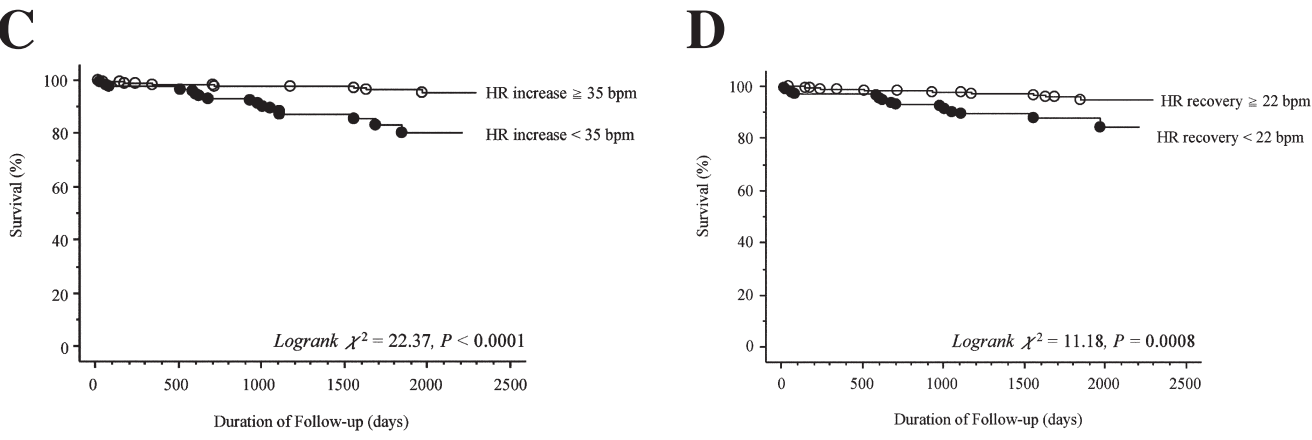

E

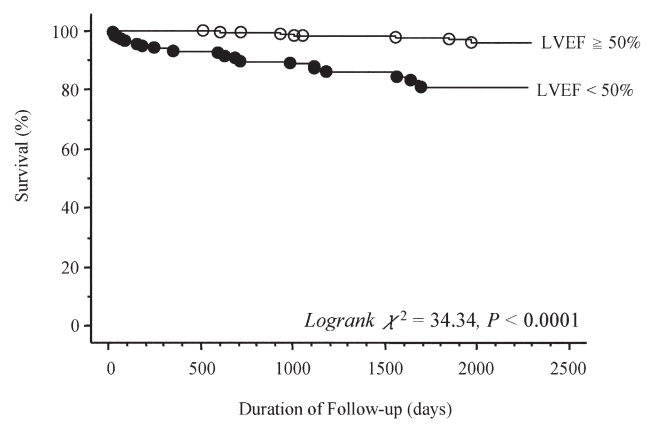

Figure. Kaplan-Meier plot relating survival peak $\mathrm{VO}_{2}(\mathbf{A}), \mathrm{VE} / \mathrm{VCO}_{2}$ slope $(\mathbf{B})$, HR increase (C), HR recovery (D), and LVEF (E).

are shown in Figure. There were significant associations between the tertiles of these parameters and mortality.

\section{Discussion}

The results of the present study indicate that both CPX parameters and HR profiles provide valuable prognostic information in cardiac patients.

CPX parameters: Since the 1980s, CPX has been applied to patients with heart 
disease to objectively assess exercise capacity, to risk stratify patients, and to assess responses to therapeutic interventions. ${ }^{12,13)}$ In 1991, Mancini, et al proposed that cardiac transplantation could be safely deferred in ambulatory patients with severe left ventricular dysfunction when the peak $\mathrm{VO}_{2}$ was $>14 \mathrm{~mL} / \mathrm{min} / \mathrm{kg}$. ${ }^{1}$ Since then, peak $\mathrm{VO}_{2}$ has been considered a key index to list for cardiac transplantation. Other investigators have also reported that peak $\mathrm{VO}_{2}$ measurement is advantageous for predicting prognosis. ${ }^{14,15)}$ Chua, et al examined the relationship between mortality and ventilatory response during symptom-limited exercise over a 2-year follow-up period in cardiac patients. ${ }^{2}$ Their data indicated that the $\mathrm{VE} / \mathrm{VCO}_{2}$ slope correlated with the severity of the heart failure. They also found that the $\mathrm{VE} / \mathrm{VCO}_{2}$ slope was an independent prognostic marker in their cardiac patients. Several studies since then have demonstrated the strong predictive value of peak $\mathrm{VO}_{2}$ and $\mathrm{VE} / \mathrm{VCO}_{2}$ slope. ${ }^{3,16-21)}$ Most patients achieve comparable arterial-venous oxygen differences when they give maximal effort. Peak $\mathrm{VO}_{2}$ has thus served as a noninvasive marker for peak cardiac output response and cardiac reserve. Yet cardiac output response is not the only factor influencing peak $\mathrm{VO}_{2}$ : limited skeletal muscle mass and perfusion also have affects. Ventilatory efficiency, meanwhile, depends on pulmonary hemodynamics and related parameters such as ventilation-perfusion mismatch, skeletal muscle ergoreceptor and peripheral chemoreceptor sensitivity, and heightened sympathetic activity. Most reports characterize the $\mathrm{VE} / \mathrm{VCO}_{2}$ slope as prognostically superior to peak $\mathrm{VO}_{2}$, and thus underscore the clinical importance of assessing ventilatory efficiency. ${ }^{2,16,18,19)}$ Because CPX parameters are closely related to hemodynamics and peripheral function, they can predict cardiovascular death.

HR profiles: There have been many reports on prognoses estimated from HR response during exercise. In the early 1970s, Ellestad, et al described chronotropic incompetence during exercise testing as a marker of poor prognosis. ${ }^{22)}$ Since then, chronotropic incompetence has been proved to be a poor predictor of survival among healthy cohorts and patients with coronary artery disease and heart failure. ${ }^{23-28)}$ Chronotropic incompetence might have been more meaningful as a marker for autonomic dysfunction in those studies. HR recovery, an index of parasympathetic activity, has been reported as another significant prognostic predictor in healthy subjects and patients with coronary artery disease and heart failure. ${ }^{29-38)}$ In 1999, Cole, et al noted that HR recovery was a strong and significant predictor of prognosis among 2,428 adults with no history of CHF or coronary revascularization. ${ }^{5)}$

HR profiles are related not only to vagal tone and autonomic imbalance but also to exercise tolerance. Patients with lower exercise tolerance tend to exhibit a lower HR increase and lower HR recovery. Autonomic imbalance, a term used to indicate a relative or absolute decrease in vagal activity or an increase in 
sympathetic activity, has been associated with an increased risk of death from cardiac and arrhythmic causes. ${ }^{7)}$ The limited number of cases of sudden death in the present study prevents us from discussing the prediction of sudden death in our subjects. HR profiles may be more useful for the prediction of sudden death than CPX parameters.

CPX parameters versus HR profiles: Robbins, et al examined how mortality related to chronotropic response and CPX parameters, especially ventilatory response, during symptom-limited exercise testing conducted by the Naughton protocol in heart failure patients, over a 1.5 -year follow-up period. ${ }^{39)}$ Ventilatory response and chronotropic response were more powerful independent predictors of cardiovascular death than peak $\mathrm{VO}_{2}$ in their study. In a study with heart failure patients by Arena, et al, $\mathrm{HR}$ recovery and $\mathrm{VE} / \mathrm{VCO}_{2}$ slope during symptomlimited exercise testing according to the treadmill Ramp protocol were both predictive of prognosis over a 1-year follow-up period. ${ }^{40)}$ Nanas, et al noted that $\mathrm{HR}$ recovery in heart failure patients was a better predictor than peak $\mathrm{VO}_{2}$ or ventilatory response during symptom-limited exercise testing according to the Bruce or modified Naughton protocol, over a 2-year follow-up period. ${ }^{41}$

These three studies concluded that HR profiles were comparable or superior to CPX as predictors of prognosis. Though HR profiles can easily be assessed as valuable markers in clinical practice, the HR profiles in our study were not superior to peak $\mathrm{VO}_{2}$ or $\mathrm{VE} / \mathrm{VCO}_{2}$ slope. The discrepancy between these earlier results and our own study might be attributable to the observation period or exercise protocol. While CPX parameters closely reflect cardiac function and peripheral function, HR profiles are more closely related to cardiac function, vagal tone, and autonomic imbalance. Peak $\mathrm{VO}_{2}$ is derived from the Fick equation, as follows: $\mathrm{VO}_{2}=$ cardiac output $\mathrm{x}$ arterial-mixed venous $\mathrm{O}_{2}$ content difference $((\mathrm{C}$ (a-v) $\mathrm{O}_{2}$ ) diff). Cardiac output equals heart rate times stroke volume. This equation implies that $\mathrm{HR}$ can be treated as a determinant of $\mathrm{VO}_{2}$. If this is so, CPX parameters might be superior to HR profiles.

Limitations: CPX parameters are known to integrate cardiac function and lung function with oxygen delivery and use in exercising muscles. Although the prognostic power of the parameters may at least partly depend on the etiology and severity of heart disease, there were too few subjects in the present study to bring out any disease-specific characteristics of the prognostic parameters individually.

In general, many studies have failed to show a significant link between exercise capacity (peak $\mathrm{VO}_{2}$ ) and LVEF in patients with chronic heart failure, ${ }^{42)}$ and it has been reported that peak $\mathrm{VO}_{2}$ is superior to LVEF as a prognostic predictor. However, in this study population, because averaged LVEF was about $60 \%$ and several patients with preserved LVEF were included, it seemed that 
LVEF was the strongest prognostic parameter.

$\beta$-Blockers have been found to improve the survival of heart failure patients in several studies. Yet $\beta$-blockers reduce resting and peak HR. The equipoise on the effect of $\beta$-blockers on HR is unresolved. ${ }^{43,44)} \mathrm{A}$ small number of patients included in our study $(37.7 \%)$ received $\beta$-blocker treatment during the study period. There was no difference between the numbers of nonsurvivors and survivors who received $\beta$-blockers. In univariate Cox proportional analyses, $\beta$-blocker use had no significance as a predictor of prognosis in earlier studies. $\beta$-Blocker use also lacked prognostic significance in our study.

Conclusions: Although heart rate profiles during exercise testing are easy to perform and useful as prognostic predictors in patients with cardiac disease, they are not superior to respiratory gas analysis.

\section{REFERENCES}

1. Mancini DM, Eisen H, Kussmaul W, Mull R, Edmunds LH Jr, Wilson JR. Value of peak exercise oxygen consumption for optimal timing of cardiac transplantation in ambulatory patients with heart failure. Circulation 1991; 83: 778-86.

2. Chua TP, Ponikowski P, Harrington D, et al. Clinical correlates and prognostic significance of the ventilatory response to exercise in chronic heart failure. J Am Coll Cardiol 1997; 29: 1585-90.

3. Koike A, Itoh $\mathrm{H}$, Kato M, et al. Prognostic power of ventilatory responses during submaximal exercise in patients with chronic heart disease. Chest 2002; 121: 1581-8.

4. Lauer MS, Okin PM, Larson MG, Evans JC, Levy D. Impaired heart rate response to graded exercise. Prognostic implications of chronotropic incompetence in the Framingham Heart Study. Circulation 1996; 93: 1520-6.

5. Cole CR, Blackstone EH, Pashkow FJ, Snader CE, Lauer MS. Heart-rate recovery immediately after exercise as a predictor of mortality. N Engl J Med 1999; 341: 1351-7.

6. La Rovere MT, Bigger JT Jr, Marcus FI, Mortara A, Schwartz PJ. Baroreflex sensitivity and heart-rate variability in prediction of total cardiac mortality after myocardial infarction. ATRAMI (Autonomic Tone and Reflexes After Myocardial Infarction) Investigators. Lancet 1998; 351: 478-84.

7. Jouven X, Empana JP, Schwartz PJ, Desnos M, Courbon D, Ducimetière P. Heart-rate profile during exercise as a predictor of sudden death. N Engl J Med 2005; 352: 1951-8.

8. Lightfoot JT, Tankersley C, Rowe SA, Freed AN, Fortney SM. Automated blood pressure measurements during exercise. Med Sci Sports Exerc 1989; 21: 698-707.

9. Koike A, Hiroe M, Adachi H, et al. Oxygen uptake kinetics are determined by cardiac function at onset of exercise rather than peak exercise in patients with prior myocardial infarction. Circulation 1994; 90: 2324-32.

10. Koike A, Yajima T, Adachi H, et al. Evaluation of exercise capacity using submaximal exercise at a constant work rate in patients with cardiovascular disease. Circulation 1995; 91: 1719-24.

11. Wasserman K, Hansen JE, Sue DY, et al. Principles of Exercise Testing and Interpretation. Baltimore, Maryland: Lippincott Williams \& Wilkins, 2005.

12. Weber KT, Janicki JS. Cardiopulmonary exercise testing for evaluation of chronic cardiac failure. Am J Cardiol 1985; 55: 22A-31.

13. Szlachcic J, Massie BM, Kramer BL, Topic N, Tubau J. Correlates and prognostic implication of exercise capacity in chronic congestive heart failure. Am J Cardiol 1985; 55: 1037-42.

14. Ponikowski P, Francis DP, Piepoli MF, et al. Enhanced ventilatory response to exercise in patients with chronic heart failure and preserved exercise tolerance: marker of abnormal cardiorespiratory reflex control and predictor of poor prognosis. Circulation 2001; 103: 967-72. 
15. Myers J, Prakash M, Froelicher V, Do D, Partington S, Atwood JE. Exercise capacity and mortality among men referred for exercise testing. N Engl J Med 2002; 346: 793-801.

16. Kleber FX, Vietzke G, Wernecke KD, et al. Impairment of ventilatory efficiency in heart failure: prognostic impact. Circulation 2000; 101: 2803-9.

17. Buller NP, Poole-Wilson PA. Mechanism of the increased ventilatory response to exercise in patients with chronic heart failure. Br Heart J 1990; 63: 281-3.

18. Arena R, Myers J, Aslam SS, Varughese EB, Peberdy MA. Peak $\mathrm{VO}_{2}$ and $\mathrm{VE} / \mathrm{VCO}_{2}$ slope in patients with heart failure: a prognostic comparison. Am Heart J 2004; 147: 354-60.

19. Francis DP, Shamim W, Davies LC, et al. Cardiopulmonary exercise testing for prognosis in chronic heart failure: continuous and independent prognostic value from VE/VCO (2) slope and peak VO (2). Eur Heart J 2000; 21: 154-61.

20. Guazzi M, De Vita S, Cardano P, Barlera S, Guazzi MD. Normalization for peak oxygen uptake increases the prognostic power of the ventilatory response to exercise in patients with chronic heart failure. Am Heart J 2003; 146: 542-8.

21. Koike A, Koyama Y, Itoh H, Adachi H, Marumo F, Hiroe M. Prognostic significance of cardiopulmonary exercise testing for 10-year survival in patients with mild to moderate heart failure. Jpn Circ J 2000; 64: 915-20.

22. Ellestad MH, Wan MK. Predictive implications of stress testing. Follow-up of 2700 subjects after maximum treadmill stress testing. Circulation 1975; 51: 363-9.

23. Ellestad MH. Chronotropic incompetence. The implications of heart rate response to exercise (compensatory parasympathetic hyperactivity?) Circulation 1996; 93: 1485-7.

24. Lauer MS, Mehta R, Pashkow FJ, Okin PM, Lee K, Marwick TH. Association of chronotropic incompetence with echocardiographic ischemia and prognosis. J Am Coll Cardiol 1998; 32: 1280-6.

25. Lauer MS, Francis GS, Okin PM, Pashkow FJ, Snader CE, Marwick TH. Impaired chronotropic response to exercise stress testing as a predictor of mortality. JAMA 1999; 281: 524-9.

26. Dresing TJ, Blackstone EH, Pashkow FJ, Snader CE, Marwick TH, Lauer MS. Usefulness of impaired chronotropic response to exercise as a predictor of mortality, independent of the severity of coronary artery disease. Am J Cardiol 2000; 86: 602-9.

27. Elhendy A, Mahoney DW, Khandheria BK, Burger K, Pellikka PA. Prognostic significance of impairment of heart rate response to exercise: impact of left ventricular function and myocardial ischemia. J Am Coll Cardiol 2003; 42: 823-30.

28. Azarbal B, Hayes SW, Lewin HC, Hachamovitch R, Cohen I, Berman DS. The incremental prognostic value of percentage of heart rate reserve achieved over myocardial perfusion single-photon emission computed tomography in the prediction of cardiac death and all-cause mortality: superiority over $85 \%$ of maximal age-predicted heart rate. J Am Coll Cardiol 2004; 44: 423-30.

29. Nishime EO, Cole CR, Blackstone EH, Pashkow FJ, Lauer MS. Heart rate recovery and treadmill exercise score as predictors of mortality in patients referred for exercise ECG. JAMA 2000; 284: 1392-8.

30. Cole CR, Foody JM, Blackstone EH, Lauer MS. Heart rate recovery after submaximal exercise testing as a predictor of mortality in a cardiovascularly healthy cohort. Ann Intern Med 2000; 132: 552-5.

31. Watanabe J, Thamilarasan M, Blackstone EH, Thomas JD, Lauer MS. Heart rate recovery immediately after treadmill exercise and left ventricular systolic dysfunction as predictors of mortality: the case of stress echocardiography. Circulation 2001; 104: 1911-6.

32. Desai MY, De la Peña-Almaguer E, Mannting F. Abnormal heart rate recovery after exercise as a reflection of an abnormal chronotropic response. Am J Cardiol 2001; 87: 1164-9.

33. Diaz LA, Brunken RC, Blackstone EH, Snader CE, Lauer MS. Independent contribution of myocardial perfusion defects to exercise capacity and heart rate recovery for prediction of all-cause mortality in patients with known or suspected coronary heart disease. J Am Coll Cardiol 2001; 37: 1558-64.

34. Morshedi-Meibodi A, Larson MG, Levy D, O'Donnell CJ, Vasan RS. Heart rate recovery after treadmill exercise testing and risk of cardiovascular disease events (The Framingham Heart Study). Am J Cardiol 2002; 90: 848-52.

35. Vivekananthan DP, Blackstone EH, Pothier CE, Lauer MS. Heart rate recovery after exercise is a predictor of mortality, independent of the angiographic severity of coronary disease. J Am Coll Cardiol 
$2003 ; 42: 831-8$.

36. Morise AP. Heart rate recovery: predictor of risk today and target of therapy tomorrow? Circulation 2004; 110: 2778-80.

37. Chen MS, Blackstone EH, Pothier CE, Lauer MS. Heart rate recovery and impact of myocardial revascularization on long-term mortality. Circulation 2004; 110: 2851-7.

38. Lipinski MJ, Vetrovec GW, Froelicher VF. Importance of the first two minutes of heart rate recovery after exercise treadmill testing in predicting mortality and the presence of coronary artery disease in men. Am J Cardiol 2004; 93: 445-9.

39. Robbins M, Francis G, Pashkow FJ, et al. Ventilatory and heart rate responses to exercise : better predictors of heart failure mortality than peak oxygen consumption. Circulation 1999; 100: 2411-7.

40. Arena R, Guazzi M, Myers J, Peberdy MA. Prognostic value of heart rate recovery in patients with heart failure. Am Heart J 2006; 151: 851. e7-13.

41. Nanas S, Anastasiou-Nana M, Dimopoulos S, et al. Early heart rate recovery after exercise predicts mortality in patients with chronic heart failure. Int J Cardiol 2006; 110: 393-400.

42. Witte KK, Nikitin NP, De Silva R, Cleland JG, Clark AL. Exercise capacity and cardiac function assessed by tissue Doppler imaging in chronic heart failure. Heart 2004; 90: 1144-50.

43. Khan MN, Pothier CE, Lauer MS. Chronotropic incompetence as a predictor of death among patients with normal electrograms taking beta blockers (metoprolol or atenolol). Am J Cardiol 2005; 96: 1328-33.

44. Witte KK, Cleland JG, Clark AL. Chronic heart failure, chronotropic incompetence, and the effects of beta blockade. Heart 2006; 92: 481-6. 